\title{
DO ENSINO FUNDAMENTAL DE 8 PARA O DE 9 ANOS DE DURAÇÃO: OS EMBATES SOBRE A IDADE PARA O INGRESSO NAS ESCOLAS PARANAENSES
}

\author{
Simone de Fátima Flach ${ }^{1}$ \\ Universidade Estadual de Ponta Grossa - UEPG
}

\section{RESUMO}

O texto apresenta a realidade paranaense tendo em vista a garantia da oferta do ensino fundamental a partir da década de 1990, chegando aos principais embates ocorridos nos contextos político-educacional e judicial face ao processo de implementação do Ensino Fundamental de 9 anos. São analisados os dados da oferta do ensino fundamental, os principais documentos normativos que orientaram as matrículas no período, bem como algumas medidas jurídicas que versaram sobre a implantação do ensino fundamental de 9 anos no Paraná. As análises demonstram que a ampliação do ensino fundamental ocorreu sob a lógica dos interesses de classe reafirmando que o direito à educação ainda não foi assegurado igualmente para todos os cidadãos.

Palavras-chave: ensino fundamental de 9 anos; educação obrigatória; direito à educação; política educacional.

\section{PRIMARY EDUCATION FROM EIGHT TO NINE YEARS: DISCUSSIONS ABOUT THE AGE FOR ENTERING SCHOOLS IN PARANÁ}

\begin{abstract}
The text presents the reality of Parana with a view to ensuring the provision of basic education since 1990, to the main discussions occurred in educational and political contexts over the judicial process of implementing the Primary Education for 9 years. This article analyzes the data of the supply of primary education, the main normative documents that have guided the enrollment period, as well as some legal measures to deal with the implementation of basic education of nine years in Paraná. The analysis shows that the expansion of primary education took place in the logic of class interests, reaffirming that the right to education hasn't been provided equally to all citizens.

Key-works: 9 years of primary education; compulsory education; right to education; educational policy.
\end{abstract}

\section{O atendimento do ensino fundamental no Paraná}

A política educacional paranaense, a partir dos anos de 1990, em especial aquela direcionada ao ensino fundamental, esteve atrelada aos ditames das reformas educacionais de caráter mais geral, evidenciando um alinhamento político-ideológico com as orientações dos organismos multilaterais que se faziam presentes para o setor educacional dos países mais periféricos.

Inserida organicamente no contexto das reformas educacionais da década de 1990 e tendo governos que assumiram tais defesas em prol da reorganização administrativa, ampliação da oferta educativa e melhoria dos resultados obtidos, a educação paranaense tornou-se solo fértil para a implementação de políticas de cunho neoliberal 
(GONÇALVES, 1994; AMARAL, 1996; HIDALGO, 1998; SANTOS, 1998; SILVA, 1998, GORNI, 1999; SOUZA, 2001; ZANARDINI, 2001). Algumas áreas sofreram maiores impactos das políticas educacionais implementadas, evidenciando o aporte teórico de sustentação das ações, dentre as quais se podem citar: a gestão do sistema educacional e das escolas; o processo de municipalização dos anos iniciais do ensino fundamental; a descentralização/desconcentração de recursos financeiros; a readequação do fluxo escolar e a formação de professores (esta evidenciada na criação da Universidade do Professor, em Faxinal do $\mathrm{Céu}^{2}$ ).

A partir da gestão estadual do período 1991 - 1994 a política educacional paranaense incorporou, gradativamente, os princípios da gestão empresarial introduzindoos na gestão escolar (SANTOS, 1998; SOUZA, 2001). Tais princípios se aprofundaram nos anos posteriores, sendo objeto de inúmeras pesquisas de caráter crítico que evidenciaram os pressupostos da Gestão de Qualidade Total na educação paranaense, demonstrando como o pensamento capitalista adentra no espaço escolar. (GONÇALVES, 2004; MUNHOZ, 2002);

Em meados da década de 1980, o Brasil foi tomado pela retórica da globalização da economia, apresentando características muito peculiares em relação ao chamado neoliberalismo que se fortalecia nos países desenvolvidos, pois incorporou orientações de flexibilização mercadológica e assumiu a função de Estado normatizador.

A retórica neoliberal, assim como as orientações dos Organismos Internacionais, encontrou guarida junto aos responsáveis pelas propostas educacionais paranaenses, quando houve a efetivação do Projeto Qualidade do Ensino Público, do Programa de Capacitação de Professores ocorrido na Universidade do Professor em Faxinal do Céu e do Programa de Adequação Idade Série.

Os pressupostos da retórica capitalista aparecem na iniciativa de organizar a educação paranaense pautada nas orientações dos Organismos Multilaterais, principalmente com o Projeto Qualidade no Ensino Público do Paraná, a partir do ano de 1994. Esse Projeto foi instituído através de parceria entre o governo do estado do Paraná e do Banco Mundial, com o apoio do governo federal. Em síntese, essa parceria induziu os municípios a assumir a responsabilidade por escolas que ofertavam as séries iniciais do $1^{\circ}$ grau, a manutenção da organização do Ciclo Básico de Alfabetização e a substituição de professores estaduais que deixavam a rede ou se aposentavam. (GORNI, 1999).

A precariedade dos municípios, tanto financeira como técnico-pedagógica, conforme acontece em outros municípios brasileiros, contribuiu para a adesão ao Programa, acelerando o processo de municipalização no estado. Segundo SANTOS (1998) em 1994, dos 371 municípios paranaenses 268 haviam aderido totalmente à municipalização e em 52 ocorria municipalização parcial. A municipalização dos anos iniciais do ensino fundamental, fortalecida por aspectos ideológicos da administração capitalista, fez parte de um projeto governamental de reestruturação do Sistema de Ensino paranaense e contribuiu para que os municípios exercessem uma aparente autonomia.

Assim, a oferta do ensino fundamental na década de 1990, em especial dos anos iniciais, no estado do Paraná foi sendo transferida, gradativamente, aos municípios, por meio de adesão voluntária, ficando a rede estadual, nos "municípios parceiros", responsável pela oferta dos anos finais.

Embora tenha ocorrido um esforço para que a totalidade dos municípios paranaenses assumisse a oferta dos anos iniciais do ensino fundamental, alguns foram resistentes e, mesmo com significativa redução no atendimento, a Rede Estadual permaneceu presente na oferta. 
A presença das redes estadual e municipal públicas nos diversos municípios paranaenses indica como as duas redes absorveram ou transferiram as matrículas para o outro ente administrativo e organizaram o atendimento da escolaridade obrigatória conforme as orientações legais, político-educacionais e necessidade e/ou possibilidade financeira no período.

Dessa forma, a oferta da escolaridade obrigatória no contexto paranaense vinculouse ao processo de municipalização dos anos iniciais do ensino fundamental ocorrido via adesão ao Programa de Parceria Educativa implementado pela Secretaria de Estado da Educação. A promulgação da Lei 9424/96, que regulamentou o Fundo de Manutenção e Desenvolvimento do Ensino Fundamental e Valorização do Magistério - Fundef, contribuiu para que os governos municipais também tivessem interesse em ampliar suas matrículas, visando o recebimento de uma parcela maior dos recursos oriundos do Fundo então criado.

A ampliação do atendimento educacional nas redes municipais, conforme sugerido por Guimarães em 1998 e reafirmado em 2004, ocorreu devido ao grau de dependência financeira dos municípios relativa às transferências constitucionais (FPM - Fundo de Participação dos Municípios). Assim, a municipalização ocorreu muito mais pelo caráter confiscatório do Fundef do que pela preocupação dos administradores municipais quanto à melhoria da educação.

Essa característica de municipalização induzida ocorreu em todo o território nacional, não sendo exclusividade do estado do Paraná. Contudo, no caso paranaense, houve a fragmentação da oferta do ensino fundamental em duas etapas denominadas "Anos Iniciais" e "Anos Finais". Dessa forma, a etapa da educação básica, prevista na legislação para ocorrer de forma contínua e em regime de colaboração entre estados e municípios, foi dividida na maioria das regiões paranaenses.

A Tabela 1 evidencia o crescimento do atendimento pelos municípios em contraposição à redução do atendimento pelo poder público estadual em relação aos anos iniciais do Ensino Fundamental:

TABELA 1 - EVOLUÇÃO DE MATRÍCULAS NOS ANOS INICIAIS DO ENSINO FUNDAMENTAL NO PARANÁ POR DEPENDÊNCIA ADMINISTRATIVA - 1997 - 2008

\begin{tabular}{|c|c|c|c|c|c|}
\hline Ano & Total & Federal & Estadual & Municipal & Privada \\
\hline \multirow[t]{2}{*}{1997} & 977.687 & 1.037 & 151.942 & 747.896 & 76.812 \\
\hline & $100 \%$ & & $16 \%$ & $76 \%$ & $8 \%$ \\
\hline \multirow[t]{2}{*}{1998} & 972.458 & - & 129.070 & 769.074 & 74.314 \\
\hline & $100 \%$ & & $13 \%$ & $79 \%$ & $8 \%$ \\
\hline \multirow[t]{2}{*}{1999} & 937.330 & - & 105.778 & 761.093 & 70.459 \\
\hline & $100 \%$ & & $11 \%$ & $81 \%$ & $8 \%$ \\
\hline \multirow[t]{2}{*}{2000} & 907.086 & - & 89.416 & 749.815 & 67.855 \\
\hline & $100 \%$ & & $10 \%$ & $83 \%$ & $7 \%$ \\
\hline \multirow[t]{2}{*}{2001} & 900.133 & - & 78.407 & 754.529 & 67.197 \\
\hline & $100 \%$ & & $9 \%$ & $84 \%$ & $7 \%$ \\
\hline \multirow[t]{2}{*}{2002} & 891.518 & - & 48.128 & 777.714 & 65.676 \\
\hline & $100 \%$ & & $5 \%$ & $88 \%$ & $7 \%$ \\
\hline \multirow[t]{2}{*}{2003} & 885.831 & - & 44.064 & 774.596 & 67.171 \\
\hline & $100 \%$ & & $5 \%$ & $87 \%$ & $8 \%$ \\
\hline
\end{tabular}




\begin{tabular}{|c|c|c|c|c|c|}
\hline \multirow[t]{2}{*}{2004} & 878.995 & - & 40.889 & 768.419 & 69.687 \\
\hline & $100 \%$ & & $5 \%$ & $87 \%$ & $8 \%$ \\
\hline \multirow[t]{2}{*}{2005} & 857.695 & - & 37.460 & 749.290 & 70.945 \\
\hline & $100 \%$ & & $4 \%$ & $88 \%$ & $8 \%$ \\
\hline \multirow[t]{2}{*}{2006} & 838.928 & - & 30.984 & 735.958 & 71.986 \\
\hline & $100 \%$ & & $4 \%$ & $87 \%$ & $9 \%$ \\
\hline \multirow[t]{2}{*}{2007} & 866.588 & - & 26.399 & 760.916 & 79.273 \\
\hline & $100 \%$ & & $3 \%$ & $88 \%$ & $9 \%$ \\
\hline \multirow[t]{2}{*}{2008} & 870.574 & - & 24.222 & 760.963 & 85.389 \\
\hline & $100 \%$ & & $3 \%$ & $87 \%$ & $10 \%$ \\
\hline
\end{tabular}

Fonte: MEC, INEP, Censo Escolar do Período

Os dados demonstram que houve significativa redução do atendimento dos anos iniciais na rede estadual (de 16\% em 1997 para 3\% em 2008), enquanto as redes municipais apresentaram crescimento (de 76\% em 1997 para 87\% em 2008). Isso significa que o processo de municipalização dos anos iniciais do ensino fundamental, a implantação do Fundef e o recuo da oferta de vagas na rede estadual foram determinantes para que os municípios assumissem a responsabilidade de forma definitiva por esta etapa da educação básica.

Quanto à rede privada, o percentual de atendimento pouco alterou de 1997 a 2005, oscilando o número de matriculados entre 8 e $7 \%$. No entanto, houve um aumento a partir de 2006, chegando em 2008 ao patamar de 10\%. Esse leve aumento percentual no atendimento dos anos iniciais do ensino fundamental pode ser justificado pela implantação do Ensino Fundamental de 9 anos e as controvérsias surgidas em razão da idade de ingresso na nova organização da escolaridade obrigatória. Enquanto as orientações nacionais versavam para o ingresso com 6 anos completos, a rede privada impetrou por via judicial solicitação para a matrícula de alunos com 5 anos de idade. Como a rede pública (estadual e municipal) procurava matricular todas as crianças com 6 anos completos, a rede privada matriculou, antecipadamente, crianças com 5 anos de idade a completarem 6 anos até o dia 31 do ano em que se efetivou a matrícula, fato esse que será explicitado ao longo do texto.

Como conseqüência da ampliação do atendimento dos anos iniciais nas redes municipais e o seu recuo na rede estadual, houve aumento do atendimento dos anos finais pelo Estado, evidenciando-se a ruptura ocorrida nessa etapa da educação básica no contexto paranaense. Assim, os anos iniciais, que demandam menor estrutura didáticopedagógica (espaço físico, bibliotecas menores, não exigência de laboratórios, professores menos qualificados - formação de nível médio) ficou sob a responsabilidade dos municípios, enquanto os anos finais, que necessitam de maior estrutura (espaço físico e materiais esportivos para a prática de educação física, por exemplo, laboratórios, bibliotecas com acervo mais específico, professores com formação em nível superior) foi assumida pela rede estadual.

Considerando que a ampliação do ensino fundamental foi prevista de forma a incluir mais um ano inicial, o direito à educação para essa fase específica tem ficado sob a responsabilidade dos municípios, os quais assumem mais alunos extrapolando sua capacidade financeira e pedagógica para a oferta de um trabalho educativo de maior qualidade. Por isso, a discussão sobre a ampliação do ensino fundamental de 8 para 9 anos de duração e a fixação da idade para o ingresso nesta etapa não é questão que se esclareça sem conflitos. Em uma sociedade capitalista, interesses de classe se mostram contraditórios 
e são determinantes em todos os setores, sociais, econômicos, produtivos e, não deixa de ser diferente nas propostas político-educacionais. Os dados apresentados na Tabela 2 evidenciam essas contradições;

TABELA 2 - MATRÍCULAS NO ENSINO FUNDAMENTAL DE 8 E DE 9 ANOS NO PARANÁ POR DEPENDÊNCIA ADMINISTRATIVA

\begin{tabular}{|c|c|c|c|c|c|}
\hline Ano & $\begin{array}{c}\text { Organização } \\
\text { do Ensino } \\
\text { Fundamental }\end{array}$ & Federal & Estadual & Municipal & Privada \\
\hline \multirow{2}{*}{2005} & EF 8 anos & 476 & 741.430 & 647.468 & 137.780 \\
\hline \multirow{2}{*}{2006} & EF 9 anos & - & - & $\mathbf{1 2 6 . 3 7 5}$ & - \\
\hline \multirow{2}{*}{2007} & EF 8 anos & - & 760.016 & 638.977 & 138.539 \\
\hline & EF 9 anos & - & - & $\mathbf{1 2 2 . 3 0 1}$ & $\mathbf{7 0}$ \\
\hline \multirow{2}{*}{2008} & EF 8 anos & 477 & 752.679 & 701.536 & 130.089 \\
\hline & EF 9 anos & - & - & $\mathbf{8 2 . 5 9 5}$ & $\mathbf{1 0 . 4 2 7}$ \\
\hline & EF 8 anos & - & 752.395 & 584.783 & 125.728 \\
\hline & EF 9 anos & $\mathbf{4 9 1}$ & $\mathbf{3 2 2}$ & $\mathbf{1 9 8 . 9 0 9}$ & $\mathbf{2 8 . 2 2 4}$ \\
\hline
\end{tabular}

Fonte: MEC, INEP, Censo Escolar do período

A análise dos dados da rede privada indica que, de 2006 para 2007, a ampliação do ensino fundamental contribuiu para um salto no número de matrículas nessa organização (de 70, em 2006, para 10.427 no ano de 2007). Tendência também verificada no ano de 2008, quando as matrículas chegaram ao patamar de 28.224. Essa distorção pode ser justificada devido ao fato de que, historicamente, a rede privada já atendia crianças de 6 anos de idade no ensino fundamental de 8 anos e, com o aval do Poder Judiciário no ano de 2007, pôde matricular aquelas que completavam 6 anos até o dia 31 de dezembro do ano em curso. Tal posicionamento também foi mantido para as matrículas do ano de 2008. Esse fato pode ser associado a outro também significativo na forma como a sociedade paranaense entendia a nova proposta: que o primeiro ano da nova organização seria apenas a inclusão da pré-escola ao ensino fundamental, induzindo as famílias a acreditarem que, no caso de seus filhos permanecerem na educação infantil, os mesmos estariam "perdendo" um ano da escola, ficando em atraso escolar em relação àquelas crianças que ingressariam no ensino fundamental. Esse entendimento é integrante do pensamento de parte significativa da população brasileira, fato esse evidenciado quando em 2012, em atendimento a Resolução $\mathrm{n}^{\circ} 01$ de 14 de janeiro de 2010 do Conselho Nacional de Educação, as escolas brasileiras matricularam no ensino fundamental apenas as crianças com 6 anos completos até do dia 31 de março e as ações judiciais proliferaram em todo o território brasileiro. A realidade já vivida no contexto paranaense alertou, de forma antecipada, os possíveis embates atualmente em curso no cenário nacional.

Embora a oferta e o atendimento dos anos iniciais da escolaridade obrigatória estejam centrados no poder público municipal, a influência da rede privada, em especial das grandes escolas, detentoras de maior aporte financeiro, se tornou significativa nos encaminhamentos e defesas sobre o ingresso ou não de crianças de 5 anos no ensino fundamental. 


\section{O corte etário em discussão}

No contexto das discussões sobre a escolaridade obrigatória no Paraná e, em especial relativo à sua ampliação, o corte etário para o ingresso nessa etapa se mostra determinante nas orientações e discussões sobre o Ensino Fundamental de 9 anos.

Por isso é importante que as orientações sobre a idade de ingresso sejam conhecidas para oferecer um entendimento sobre as contradições ocorridas na implantação da escolaridade ampliada. Além da proclamação oficial do texto normativo, sua execução se mostra eivada de concepções, crenças, interesses, que o utilizam conforme os objetivos pretendidos. Nesse sentido, o corte etário para o ingresso no ensino fundamental mostra como o atendimento do acesso à escolaridade obrigatória foi se constituindo no contexto paranaense.

Inserido no contexto das reformas educacionais da década de 90, o Conselho Estadual de Educação do Paraná aprovou, em 09 de outubro de 1996, a Deliberação no 006/96, visando consolidar as normas relativas à matrícula, transferência e promoções de alunos, adaptação, aproveitamento, revalidação e equivalência de estudos no ensino de $1^{\circ} \mathrm{e}$ $2^{\circ}$ graus.

O artigo 10 da Deliberação 006/96 estabelecia que "para a matrícula inicial na $1^{\text {a }}$ série do $1^{\circ}$ grau, o candidato deverá ter a idade mínima de sete (7) anos completos." Essa previsão estava em plena consonância com a prática educacional de matricular as crianças a partir dos 7 anos de idade na escola regular. No entanto, o parágrafo único do mesmo artigo previa que depois de atendidas as crianças com sete anos completos, e havendo disponibilidade de vagas, poderiam "ser matriculados na primeira série do Ensino Regular de $1^{\circ}$ Grau, alunos que vierem a completar seis (06) anos até trinta e um (31) de março do ano civil em curso". Essa previsão possibilitou a prática de matricular crianças com 6 anos de idade no ano inicial do ensino fundamental.

Ao possibilitar a matrícula de crianças com 6 anos de idade no ensino fundamental (de oito anos de duração), o Conselho Estadual de Educação abriu a possibilidade de reivindicação posterior da inclusão de crianças de 5 anos de idade no ensino fundamental de 9 anos. Nesse contexto, a questão significativa não considerada integralmente foi a redução inadvertida do direito das crianças à educação infantil, o que acarretaria mais tarde grande embate social, político e jurídico no estado do Paraná.

Em 11 de dezembro de 1998, o Conselho Estadual de Educação expediu a Deliberação 005/98, sobre matrícula inicial, por transferência, em regime de progressão parcial, aproveitamento de estudos: classificação, reclassificação e adaptações; revalidação e equivalência de estudos feitos no exterior; regularização de vida escolar, a qual substituiu a Deliberação 006/96, até então em vigor e tinha a seguinte norma para o ingresso no ensino fundamental: " Para matrícula inicial na $10^{\text {a }}$ série do Ensino Fundamental o candidato deverá ter 07 (sete) anos de idade ou facultativamente, seis anos completos.". Essa modificação introduzida, relativa à data de corte para a matrícula, pouco modificou a realidade em relação à previsão anterior, devido à possibilidade de o período de matrículas ser de responsabilidade do estabelecimento de ensino. Com isso, a exigência de 6 anos completos não foi utilizada igualmente em todas as realidades.

Em 01 de outubro de 2001, nova alteração em relação ao ingresso no ensino fundamental ocorreu com a Deliberação 09/01, com alterações relativas à matrícula para o Sistema Estadual de Ensino. Posteriormente, em razão da implantação obrigatória do ensino fundamental de 9 anos no estado do Paraná, o corte etário foi mantido nas orientações do Conselho Estadual de Educação, mas com algumas modificações conforme determinações judiciais. 
Essa Deliberação previu, em seu artigo $7^{\circ}$, o corte etário da seguinte forma: "Para matrícula de ingresso na 1. a série do Ensino Fundamental o candidato deverá ter 07 (sete) anos de idade ou facultativamente, seis anos completos até o dia 01 de março do ano letivo em que cursará esta série."

O ingresso na $1^{a}$ série do Ensino Fundamental, previsto na Deliberação 09/01 vigorou até o ano de 2006, quando houve a previsão da obrigatoriedade da ampliação dessa etapa no estado do Paraná.

As normas relativas à matrícula inicial no período 1996 - 2006, possibilitaram a prática, em escolas privadas, de matricular crianças aos 6 anos de idade no ensino fundamental. Inclusive, muitos alunos matriculados na $1^{\mathrm{a}}$ série nessas escolas migravam para as escolas públicas, as quais não ofereciam a matrícula para a referida faixa etária, criando uma distorção entre a possibilidade de ingresso entre aqueles que podiam pagar o ensino privado e aqueles que dependiam do ensino público. Essa prática beneficiava os filhos da classe economicamente mais privilegiada em detrimento daqueles que não tinham possibilidades financeiras de arcar com as despesas relativas ao ingresso na escola privada. O direito à educação, portanto, era assegurado de maneira diferenciada, conforme a classe da qual o aluno advinha, ocorrendo o que poderíamos denominar de rebaixamento da cidadania para determinados grupos sociais, visto que as instituições públicas responsáveis não poderiam cumprir sua função de assegurar igualdade de oportunidade de ingresso na educação formal para a totalidade da população. E, para além dessa questão relativa apenas ao ingresso diferenciado no ensino fundamental, a educação infantil também sofreu um achatamento, uma vez que, com o ingresso antecipado, mesmo aqueles mais privilegiados economicamente tinham reduzida a sua permanência nessa etapa.

Essa situação se compatibiliza com a análise realizada por Aldaíza Sposati sobre a assistência social no Brasil quando afirma que o entendimento sobre a cidadania encontrase no limite entre "condições objetivas e possibilidades diferenciadas de acesso à efetivação de sua cidadania" (SPOSATI, 1989, p. 11 - 12). Nesse sentido ficou criado (e aceito socialmente) um sistema paralelo, onde o "direito de alguns" torna-se "não direito" para outros. Essa compreensão equivocada fundamenta ações educacionais e políticas, contribuindo para o fortalecimento da divisão entre os indivíduos que compõem uma mesma sociedade.

Nesse contexto, os documentos emanados dos órgãos governamentais (o Conselho Estadual de Educação não deixa de ser um desses órgãos), trazem em seu bojo alguns significados nem sempre perceptíveis à classe dominada, ou, como diria Gramsci, "o 'certo' de uma cultura evoluída torna-se 'verdadeiro' nos quadros de uma cultura fossilizada e anacrônica (...)" (GRAMSCI, 2006, p. 44). Assim, o pensamento da classe dominante de que seus filhos podem e devem ter maiores oportunidades educacionais que os demais foi validado pela autorização facultativa de ingresso no ensino fundamental aos 6 anos de idade.

O índice de ideologização do discurso e também das práticas materiais do Estado é portanto flutuante, variável e diversificado segundo as classes e frações de classe às quais se dirige o Estado e sobre as quais age. A verdade do poder escapa freqüentemente às massas populares, não porque o Estado a esconda, mascare expressamente; sim, porque, por razões infinitamente mais complexas, as massas não conseguem compreender o discurso do Estado às classes dominantes.( POULANTZAS, 2000. p. 31 - 32) 
O papel decisivo das normas orientadoras reproduz as relações de classe existentes na sociedade paranaense e fortalece as políticas públicas para o setor educacional após a década de 1990. Como a oferta de educação infantil não era prioridade na política educacional paranaense, estadual e municipal, a maioria das crianças que não ingressavam no ensino fundamental aos 6 anos de idade também não era atendida na educação infantil. Assim, tais crianças eram prejudicadas duplamente: pela impossibilidade de ingresso tanto no ensino fundamental quanto na educação infantil, ocorrendo uma fragilização de seu direito à educação.

Dessa forma, o direito à educação das crianças de 6 anos de idade foi atendido conforme a classe social de onde ela advinha. Aos filhos da classe dominante era cumprido o direito à educação infantil, sob a responsabilidade das famílias e aos filhos da classe trabalhadora o mesmo direito era tolhido, em razão da falta de possibilidades financeiras dos municípios ou atendido conforme os interesses políticos de cada realidade.

Algumas vezes, a alternativa encontrada para amenizar a situação do atendimento foi o repasse de recursos públicos para entidades assistenciais comunitárias ou filantrópicas, ou aumento do número de crianças por turma, além do atendimento em turno parcial em lugar do integral ${ }^{3}$. Nas instituições assistenciais o critério para o ingresso situase, historicamente, na esfera dos mais necessitados ou desamparados ${ }^{4}$.

Após a sanção da Lei Federal 11.274 em fevereiro de 2006, o Conselho Estadual de Educação promoveu estudos a respeito da questão e, seguindo o direcionamento dado pelos Pareceres do Conselho Nacional de Educação, aprovou em 09 de junho de 2006 a Deliberação 03/06 e a Indicação 01/06, estabelecendo as normas relativas à implantação do Ensino Fundamental de 9 anos no Sistema Estadual de Ensino do Paraná. A Indicação 01/06 tece algumas considerações a respeito da importância do Ensino Fundamental de 9 anos e o justifica a partir de questão de direito, questão política e questão pedagógica, as quais considera fundamentais.

A questão de direito, que visa a equidade social, não evidencia considerações a respeito de as políticas públicas serem definidas a partir do já existente e que isso implica na desestabilização de direitos (ou crença de direitos) já consolidados no seio da prática social. A superação da desigualdade social e educacional não aparece nas orientações do Conselho Estadual de Educação do Paraná.

Segundo Bobbio (2004, p. 20) "Não se pode afirmar um novo direito em favor de uma categoria de pessoas sem suprimir algum velho direito, do qual se beneficiavam outras categorias de pessoas". Nessa perspectiva, o ingresso diferenciado até então recorrente na educação paranaense precisaria ser revisto, posto que não mais pudesse existir a figura da "facultatividade do ingresso antecipado". O ensino fundamental (ampliado) deveria ser obrigatório para todos e constituir-se em verdadeiro direito público subjetivo. Essa parece ter sido a tentativa expressa no art. 12 da Deliberação 03/06:

Art. 12 - Para matrícula de ingresso no $1 .^{\circ}$ ano do ensino fundamental de 9 anos de duração o educando deverá ter seis anos completos ou a completar até $1^{\circ}$ de março do ano letivo em curso.

$\S 1 .^{\circ}$ - O aluno que estiver cursando a educação infantil e completar seis anos de idade no decorrer do ano letivo não poderá ingressar no ensino fundamental nesse mesmo ano. (PARANÁ, 2006)

No entanto, não foi o que ocorreu, pois tendo em vista a prática educacional das escolas privadas de matricular crianças com 6 anos no ensino fundamental (de 8 anos de duração), já havia organização da educação infantil que validava tal prática e, como com a ampliação estava prevista na antecipação, ou seja, nos anos iniciais e não nos anos finais, 
houve repercussão negativa para a implantação da nova organização da escolaridade obrigatória no estado.

Devido à previsão do parágrafo $1^{\circ}$ do Art. 12 da Deliberação 03/06, as instituições privadas e os pais de seus alunos alegavam que a criança estava sendo impedida de entrar no ensino fundamental e com isso deveria "repetir" a pré-escola ou a última etapa da educação infantil. Tendo em vista esse fato, o Sindicato das Escolas particulares do Paraná - SINEPE, solicitou ao CEE/PR a revisão das normas até então expedidas de forma a reconhecer o última etapa da educação infantil como equivalente ao $1^{\circ}$ ano do ensino fundamental de 9 anos.

Nas redes públicas municipais houve inúmeras alegações de impossibilidade financeira para atender toda a demanda no ensino fundamental de 9 anos. Segundo informações da União dos Dirigentes Municipais de Educação do Paraná - UNDIME-PR, $80 \%$ dos municípios paranaenses não tinham condições de implantar a medida ${ }^{5}$.

Em razão das discussões e repercussões da Deliberação 03/06, o Conselho Estadual de Educação aprovou, em 01 de setembro de 2006, o Parecer 01/06 e a Deliberação 05/06, expedindo novas orientações para a implantação do ensino fundamental de 9 anos no ano de 2007. Essa norma autorizou (em caráter excepcional e exclusivamente para o ano letivo de 2007) a matrícula de alunos no ensino fundamental de 8 anos, conforme estabelecia a regra anterior: para aqueles que completassem 06 anos de idade até o dia $1^{\circ}$ de março.

Essa exceção criada pelo artigo $1^{\circ}$ da Deliberação 05/06 atendeu, momentaneamente, aos interesses tanto das escolas privadas como de pais de alunos, os quais defendiam a manutenção do Ensino Fundamental de 8 anos para que os alunos matriculados na última etapa da educação infantil pudessem ingressar naquela etapa da educação básica, independente de terem completado 6 anos. Também atendeu, através do artigo $2^{\circ}$, as reivindicações dos municípios paranaenses que não estavam financeiramente habilitados a ampliar a oferta de matrículas no ensino fundamental, possibilitando maior prazo para as adequações necessárias, as quais deveriam ser previstas em "projeto de implantação" a ser apresentado e aprovado pela Secretaria de Estado da Educação

Tanto o teor da Deliberação 05/06 quanto do Parecer 01/06 não deixam dúvidas sobre os conflitos vividos internamente no Conselho Estadual de Educação em razão dos interesses em disputa naquele momento histórico no contexto educacional paranaense. Houve flexibilização das normas, numa evidente tentativa de conter as discussões de grupos, senão antagônicos, no mínimo divergentes em relação ao corte etário e a ampliação do ensino fundamental em andamento.

Os Conselheiros são seres humanos inseridos em determinados grupos da sociedade e, enquanto representantes desses grupos, exercem a função de intelectuais e como tais também representam interesses em disputa. Nesse sentido, são esclarecedoras as palavras de Antonio Gramsci:

Os intelectuais são os "prepostos" do grupo dominante para o exercício das funções subalternas de hegemonia social e do governo político, isto é: 1) do consenso "espontâneo" dado pelas grandes massas da população à orientação impressa pelo grupo fundamental dominante à vida social, consenso que nasce "historicamente" do prestígio (e, portanto, da confiança) obtido pelo grupo dominante por causa de sua posição e de sua função no mundo da produção; 2) do aparelho de coerção estatal que assegura "legalmente" a disciplina dos grupos que não "consentem", nem ativa nem passivamente, mas que é constituído por toda a sociedade na previsão de momentos de crise no comando e na direção, nos quais desaparece o consenso espontâneo. (GRAMSCI, 2006, p. 21) 
Esse entendimento nos ajuda a compreender as dificuldades e contradições existentes nas orientações sobre a implantação do Ensino Fundamental de 9 anos no Estado do Paraná. As orientações do CEE-PR não foram neutras, representaram determinada posição e evidenciaram concepções dos conselheiros e dos grupos que representavam.

A flexibilidade instaurada tornou a realidade das escolas privadas bastante diferenciada, visto que a autorização de manutenção do ensino fundamental de 8 anos para atender crianças com 6 anos completos até o dia $1^{\circ}$ de março e que haviam freqüentado a última etapa da educação infantil atendeu a uma clientela muito específica. Para as crianças que completassem 6 anos depois da data de corte (mesmo que tivessem frequientado a educação infantil no ano anterior) e para aquelas com 6 anos completos que não tivessem freqüentado a educação infantil deveria ser ofertado o $1^{\circ}$ ano do ensino fundamental de 9 anos.

Outra questão estava posta naquele momento: as escolas cujas mantenedoras eram grupos de maior capital financeiro implantaram o Ensino Fundamental de 9 anos e mantiveram a organização anterior para atender a demanda específica, enquanto as mais modestas, sem condições financeiras para manter as duas formas de atendimento mantiveram a oferta do Ensino Fundamental de 8 anos e ainda, conforme "acordos" com as grandes instituições, direcionavam alunos para serem atendidos conforme o interesse dos pais. O mesmo acontecia com as Instituições que ofertavam apenas a Educação Infantil, pois eram levadas a redirecionar seus alunos da última etapa da educação infantil para as escolas que ofertavam o $1^{\circ}$ ano do ensino fundamental de 9 anos.

Algumas escolas, ainda, sugeriam aos pais o ajuizamento de Ação específica solicitando ao Poder Judiciário Proteção Liminar para a matrícula antecipada. Assim, os interesses dos pais e do Capital estariam protegidos.

Às crianças com destino para as Escolas Públicas restava a matrícula conforme a possibilidade financeira e interesses políticos de cada realidade ou, caso as famílias arcassem com as despesas, também solicitar proteção judicial para a matrícula. A desigualdade no atendimento e caos educacional instaurou-se no Estado do Paraná.

Assim, um grupo de 14 escolas privadas ajuizou ação - Mandado de Segurança, na $1^{a}$ Vara da Fazenda Pública e de Falências do Foro Central da Comarca da Região Metropolitana de Curitiba, solicitando matricular no Ensino Fundamental de 9 anos, as crianças que completassem 6 anos até o dia 31 de dezembro do ano de 2007. Tendo a Medida Liminar sido concedida, maior controvérsia ocorreu no contexto educacional em tela, pois além da desigualdade de classe já evidente, a desigualdade também se instaurou dentro daquela atendida nas escolas privadas: aquelas protegidas pela Medida Liminar e aquelas não protegidas. Os interesses impostos pelo capital mostraram-se fortes e, ainda, protegidos pelo Poder Judiciário.

Devido à situação totalmente atípica em andamento, em que a desigualdade estava instaurada e validada, o Ministério Público do Estado do Paraná, através da Promotoria de Justiça de Proteção à Educação, aforou Ação Civil Pública visando: impedir a fixação do corte etário no âmbito do Sistema Estadual de Ensino; a expedição, pelo CEE-PR, de regras de transição do Ensino Fundamental de 8 para o de 9 anos e, ainda, impedir que a implantação da nova organização fosse postergada para além de 2007.

A todas as escolas do Sistema Estadual de Ensino ${ }^{6}$ foi imposta a matrícula de crianças com 5 anos de idade (a completar 6 anos até o dia 31 de dezembro) no ensino fundamental de 9 anos e a manutenção do ensino fundamental de 8 anos com matrícula aos 6 anos de idade conforme estabelecido na Deliberação 09/01.

Em cumprimento à determinação judicial o CEE-PR aprovou, em 14/04/07, a alteração do art. 12 da Deliberação 03/06, conforme previsto na Deliberação $n^{\circ}$ 02/07: 
Art. . $1^{\circ}$ Fica alterado o art. 12 e seus parágrafos, da Deliberação $\mathrm{n}^{\circ}$ 03/06-CEE, que passa a ter a seguinte redação:

Art. 12 Para a matrícula de ingresso no $.1^{\circ}$ ano do Ensino Fundamental de 9 anos de duração, o educando deverá ter 6 (seis) anos completos ou a completar no início do ano letivo.

Parágrafo único- Atendida a matrícula dos alunos com 6 (seis) anos completos ou a completar no início do ano letivo, admite-se, em caráter excepcional, o acesso ao ensino fundamental de crianças que completem seis anos no decorrer do ano letivo, desde que atendidos os seguintes requisitos:

a) termo de responsabilidade pela antecipação da matrícula da criança, assinado pelos pais ou responsáveis;

b) explicitação no Regimento Escolar;

c) proposta pedagógica adequada ao desenvolvimento dos alunos;

d) comprovação da existência de vagas no estabelecimento de ensino Art. $2^{\circ}$ Para o ano de 2007, ficam mantidas as normas exaradas por este Conselho Estadual de Educação visando a manutenção dos procedimentos já adotados pelas mantenedoras, desde que observado o art. 24, incisos I e VI, da Lei n 9394/96. (PARANÁ, 2007)

Juntamente com a Deliberação $n^{\circ}$ 02/07, o CEE-PR também aprovou a Indicação 01/07, a qual ressalta que "as crianças são oriundas de díspares realidades sociais e culturais" e para tanto aponta ser fundamental "o respeito aos múltiplos contextos nos quais elas se inserem a importância do espaço e da escola no qual convivem".

Parece-nos que o CEE-PR retrocedeu, revalidando a existência de oferta diferenciada conforme a origem dos alunos. Instaurou-se, novamente, a oferta de educação para classes diferenciadas.

Novamente o Ministério Público solicitou Liminar, na Ação Pública n. 402/07, visando a suspensão da Deliberação $\mathrm{n}^{\circ}$ 02/07 e procedimento criminal pelo crime de Prevaricação contra o Presidente do CEE-PR e das Conselheiras relatoras da Deliberação $n^{\circ}$ 02/07, visto, no entendimento do Ministério Público, não ter havido cumprimento da Liminar anteriormente concedida. Esse novo pedido foi concedido e, depois, em 01/06/07, novamente suspenso pelo Tribunal de Justiça do Estado. Assim, a Deliberação 02/07 foi restabelecida e também o clima de tensão entre o órgão normativo do Sistema e o Ministério Público Estadual.

No mesmo ano, e em atendimento às Decisões Judiciais, o CEE-PR exarou normas complementares sobre a questão através da Deliberação 03/07:

Art. $1^{\circ}$ A implementação progressiva do Ensino Fundamental de nove anos no Sistema de Ensino do Estado do Paraná dar-se-á até o ano de 2010, podendo as mantenedoras ofertarem, simultaneamente, o Ensino Fundamental de oito e nove anos, considerando a legislação própria. (PARANÁ, 2007)

Diante dessa nova possibilidade, houve novamente um retrocesso no processo de implantação do Ensino Fundamental de 9 anos no Paraná: as grandes redes de escolas privadas puderam manter as duas organizações para atender os interesses específicos da clientela enquanto as escolas privadas de menores recursos financeiros ficaram em situação complicada e sem condições de manter a simultaneidade. Essas escolas tiveram que optar por uma das duas organizações ou realizar "acordos" com as grandes redes. Às redes municipais foi dado maior tempo para realizarem as adequações necessárias. No entanto, devido à interpretação das liminares pelos órgãos do Ministério Público sediados nas 
diversas comarcas, houve, ainda, indução pela ampliação, conforme fatos ocorridos posteriormente.

As repercussões das Medidas Judiciais e Deliberações do CEE-PR afetaram o âmago da organização e oferta da educação infantil sob responsabilidade de mantenedoras públicas ou privadas. O aluno que tivesse freqüentado a educação infantil em 2007 e completasse 6 anos até $1^{\circ}$ de março de 2008 poderia ir para o Ensino Fundamental de 8 anos. Se completasse 6 anos depois de $1^{\circ}$ de março (até 31 de dezembro de 2008) deveria permanecer na educação infantil ou ir para o Ensino Fundamental de 9 anos. Essa questão afetou a organização da educação infantil, pois em uma mesma turma poderia haver alunos, com a mesma idade, mas com destino diferenciado. ${ }^{7}$ Além disso, a organização pedagógica também esteve afetada pelas discussões recorrentes sobre o ingresso das crianças na escola obrigatória.

Considerando as alterações das normas ocorridas no período de tensão entre o CEEPR e o Ministério Público e que, segundo o entendimento corrente, as mesmas teriam validade apenas para o ano de 2008, a Associação das Escolas de Educação Infantil de Curitiba solicitou, em 01/08/08, orientações sobre os procedimentos a serem seguidos para as matrículas no ano de 2009. Face a esse pedido, nova Deliberação foi expedida causando nova polêmica em torno da questão.

A Deliberação n ${ }^{\circ}$ 02/08, aprovada em 10/10/08, assim estabeleceu o corte etário:

Art. $1^{\circ}$ A matrícula de crianças no $1^{\circ}$ ano do Ensino Fundamental de nove anos será aos seis anos de idade completos no início do ano letivo. Parágrafo único - Situações distintas ao disposto no caput deverão ser encaminhadas para Parecer deste Conselho. (PARANÁ, 2008)

Essa nova Deliberação suscitou novamente clamor entre escolas, pais, mantenedoras e poder público. Então o Ministério Público do Estado do Paraná veiculou nota nos órgãos de imprensa e em sua home Page, datada de 05/11/2008, considerando que segundo a Liminar concedida em 07/03/2007, ainda em vigor, as matrículas deveriam ser efetivadas para "todas as crianças que completem seis anos de idade durante o ano letivo no primeiro ano de Ensino Fundamental de 9 anos".

Visando evitar nova contenda judicial sobre a questão do corte etário, o CEE-PR expediu, em 12/11/2008, Nota de Esclarecimento, a qual considerou o histórico da disputa, mantendo o posicionamento de que o início do ano letivo deveria ser considerado para a idade de ingresso no Ensino Fundamental. Mas, em razão do equilíbrio social, posicionava-se, naquele momento, de modo diverso.

Como não interessa a este Conselho estabelecer uma guerra de interpretações, gerando confusão no Sistema, mesmo convencido de que a Lei maior, a LDB e outros dispositivos legais nos dão amplo amparo, orientamos a todos os gestores de Instituições públicas e privadas que sigam as definições do Ministério Público do Paraná, permitindo a matrícula de crianças que completarem seis anos de idade ao longo do ano letivo de 2009, até que haja o julgamento definitivo da Ação Civil Pública n ${ }^{\circ} 402 / 07$, ocasião em que o CEE/PR voltará a pronunciarse sobre a matéria. (PARANÁ, 2008)

Com essa Nota de Esclarecimento, as disputas em trâmite na seara do Sistema Estadual de Ensino foram apaziguadas, o que não ocorreu, entretanto, nos Sistemas Municipais que, ou aderiram ao posicionamento do órgão normativo do Sistema Estadual ou assumiram o risco de contendas judiciais, como foi o caso do município de Ponta 
Grossa. O que ficou evidente no período foi a impossibilidade do órgão normatizador em definir normas claras que atingissem toda a população. Os interesses, explícitos ou não, estiveram em constante disputa e evidenciaram vinculação estreita com o entendimento sobre o direito à educação, quando o direito de alguns não é o direito de todos. Esse entendimento se sustenta no seu ideário conservador e amplia cada vez mais as desigualdades entre as classes sociais.

\section{Conclusão}

A disputa ocorrida demonstrou como o direito à educação é interpretado de acordo com os interesses dos envolvidos e o momento histórico vivido.

Considera-se que ao ampliar a inclusão de alunos mais novos no ensino fundamental, as adequações pedagógico-curriculares deveriam ter sido consideradas, pois o trabalho educativo com crianças de 6 e de 5 anos, apesar de diferenciado em razão dos objetivos específicos de cada etapa da educação básica, precisa ser apropriado às questões próprias da idade.

Defende-se, portanto que às crianças de 5 anos, enquanto detentoras do direito à educação infantil, deve ser assegurado todo o aporte curricular e pedagógico que as auxilie, individual e coletivamente na construção de identidades, por meio de práticas que articulem suas experiências e saberes com os conhecimentos científicos; e, para isso a organização do trabalho pedagógico a ser realizado precisa considerar os relacionamentos e interações necessários para propiciar o desenvolvimento infantil. No entanto, para as crianças integrantes do ensino fundamental, não deve haver ruptura entre uma etapa e outra e o atendimento pedagógico adequado implica em considerar as necessidades desses sujeitos, ou seja, brincar e ao mesmo tempo aprender. A investigação sobre a ampliação do ensino fundamental no contexto paranaense não indicou que as questões de ordem pedagógica tenham sido significativas em seu processo de implantação ou que tenham assumido a importância devida.

Nesse sentido, pode-se concluir que a ampliação do ensino fundamental ocorreu sob a lógica dos interesses de classe reafirmando que o direito à educação ainda não é assegurado igualmente para todos os cidadãos.

\section{Referências}

AMARAL, M. A. A qualidade da educação na "qualidade total": uma análise crítica. 1996. Dissertação (Mestrado) - Faculdade de Educação, Pontifícia Universidade Católica de São Paulo, São Paulo, 1996.

BOBBIO, N. A era dos Direitos. Rio de Janeiro: Elsevier, 2004.

GONÇALVES, A. N. A Ambiguidade da Autoridade Eleita: um olhar sobre a ação do gestor paranaense. 2004. Dissertação (Mestrado) - Universidade Estadual Paulista, Marília, SP, 2004.

GONÇALVES, M. D. S. Autonomia da escola e neoliberalismo: Estado e escola pública. 1994. Tese (Doutorado) - Faculdade de Educação, Pontifícia Universidade Católica de São Paulo, São Paulo, 1994.

GORNI, D. A. P. Sistema Estadual de Educação do Paraná: qualidade e educação. 1999. Tese (Doutorado) - Universidade Estadual Paulista, Marília, SP, 1999. 
GRAMSCI, A. Cadernos do Cárcere. vol. 2. 4 ed. Rio de Janeiro, 2006. (Tradução: Carlos Nelson Coutinho, co-edição: Luiz Sérgio Henriques e Marco Aurélio Nogueira).

GUIMARÃES, J. L.. A municipalização do ensino fundamental e o impacto da Emenda Constitucional $\mathbf{n}^{\circ} 14$ sobre os municípios paulistas. Tese (doutorado) - Universidade Estadual Paulista, Marília,1998.

GUIMARÃES, J. L.. Alguns impactos do Fundef: apontamentos e incertezas após a sua implantação. In: MARTINS, A. M.; OLIVEIRA, C.; BUENO, M. S. S. (orgs.). Descentralização do Estado e municipalização do ensino: problemas e perspectivas. Rio de Janeiro: DP\&, 2004.

HIDALGO, A. M. Tendências contemporâneas da privatização do ensino público: o caso do Estado do Paraná. 1998. Dissertação (Mestrado) - Faculdade de Educação, Pontifícia Católica de São Paulo, São Paulo, 1998.

KOSLINSKI, M. C. Universidade do Professor. In: FUJIWARA, Luis Mario; ALESSIO, Luiz Nouvel; FARAH, Marta Ferreira. 20 Experiências de Gestão Pública e Cidadania. 1998.

MUNHOZ, M. Uma Avaliação do Projeto de Correção de Fluxo nas Escolas Estaduais Paranaenses: um novo olhar sobre o sucesso escolar. 2002. . Dissertação (Mestrado) Universidade Estadual Paulista, Marília, SP, 2004.

POUlantZAS, N. O Estado, o Poder e o Socialismo. São Paulo: Paz e Terra, 2000. p. $31-32$.

SANTOS, J. M. P. As políticas governamentais para o ensino fundamental no Estado do Paraná diante dos preceitos da Constituição. 1998. Tese (Doutorado) - Faculdade de Educação, Universidade de São Paulo, São Paulo, 1998.

SILVA, I. L. F. Reforma ou contra-reforma no sistema de ensino do Estado do Paraná? Uma análise da meta da igualdade social nas políticas educacionais dos anos 90. Dissertação (Mestrado) - Faculdade de Educação, Pontifícia Católica de São Paulo, São Paulo, 1998.

SOUZA, S. A. de. Gestão Escolar compartilhada: democracia ou descompromisso?. São Paulo: Xamã, 2001.

SPOSATI, A.; FALCÃO, M. do C.: FLEURY, S. M. T. Os direitos (dos desassistitdos) sociais. São Paulo: Cortez, 1985.

ZANARDINI, I. M. S. A gestão compartilhada implementada no Estado do Paraná e as orientações do Banco Mundial (1995 - 2000). 2001. Dissertação (Mestrado) - Centro de Ciências Humanas, Letras e Artes, Universidade Estadual de Maringá, Maringá, 2001.

\section{Documentos legais e normativos:}

BRASIL, CASA CIVIL, Subchefia para assuntos jurídicos. Lei $\mathbf{n}^{\mathbf{0}} \mathbf{1 1 . 2 7 4}$, de 06 de fevereiro de 2006. (Altera a redação dos arts. 29, 30, 32 e 87 da Lei no 9.394, de 20 de dezembro de 1996, que estabelece as diretrizes e bases da educação nacional, dispondo sobre a duração de 9 (nove) anos para o ensino fundamental, com matrícula obrigatória a partir dos 6 (seis) anos de idade.)

PARANÁ. Conselho Estadual de Educação. Deliberação 01/96, aprovada em 09 de fevereiro de 1996. Programa de Adequação Idade-Série. 
PARANÁ. Conselho Estadual de Educação. Indicação 01/96, aprovada em 09 de fevereiro de 1996. Programa de Adequação Idade-Série.

PARANÁ. Conselho Estadual de Educação. Deliberação 06/96, aprovada em 09 de outubro de 1996. Consolidação das Normas Relativas a: matrícula, transferência e promoção de alunos; e adaptação, aproveitamento, revalidação e equivalência de estudos no ensino de $1^{\circ}$ e $2^{\circ}$ Graus.

PARANÁ. Conselho Estadual de Educação. Deliberação 005/98, aprovada em 11 de dezembro de 1998. Matrícula inicial, por transferência, em regime de progressão parcial, aproveitamento de estudos: classificação, reclassificação e adaptações; revalidação e equivalência de estudos feitos no exterior; regularização de vida escolar.

PARANÁ. Conselho Estadual de Educação. Deliberação 09/01 aprovada em 01 de outubro de 2001.Matrícula de ingresso, por transferência e em regime de progressão parcial; o aproveitamento de estudos; a classificação e a reclassificação; as adaptações; a revalidação e equivalência de estudos feitos no exterior e regularização de vida escolar em estabelecimentos que ofertem Ensino Fundamental e Médio nas suas diferentes modalidades.

PARANÁ. Conselho Estadual de Educação. Deliberação 03/06, aprovada em 09 de junho de 2006. Normas para a implantação do Ensino Fundamental de 9 (nove)anos de duração no Sistema Estadual de Ensino do Estado do Paraná.

PARANÁ. Conselho Estadual de Educação. Indicação n. ${ }^{\mathbf{0}}$ 01/06, aprovada em 09 de junho de 2006. Normas para a implantação do Ensino Fundamental de 9 (nove)anos de duração no Sistema Estadual de Ensino do Estado do Paraná.

PARANÁ. Conselho Estadual de Educação. Deliberação 05/06, aprovada em 01 de setembro de 2006. Orientações para a implantação do ensino fundamental de nove anos.

PARANÁ. Conselho Estadual de Educação. Parecer n. ${ }^{\circ}$ 01/06, aprovado em 01 de setembro de 2006. Orientações para a implantação do ensino fundamental de nove anos.

PARANÁ. Conselho Estadual de Educação. Deliberação n. ${ }^{0}$ 02/07, aprovada em 13 de abril de 2007. Alteração do Art. 12 da Deliberação 03/06.

PARANÁ. Conselho Estadual de Educação. Deliberação 03/07, aprovada em 15 de junho de 2007. Normas complementares para a implementação do ensino fundamental de nove anos.

PARANÁ. Conselho Estadual de Educação. Deliberação 02/08, aprovada em 10 de outubro de 2008. Norma para a matrícula no $1^{\circ}$ ano do Ensino Fundamental de nove anos, a partir do ano letivo de 2009.

PARANÁ. Conselho Estadual de Educação. Nota de Esclarecimento Público. 12 de novembro de 2008.

Notas:

${ }^{1}$ Doutora em Educação e Professora Adjunta da Universidade Estadual de Ponta Grossa (UEPG). e-mail: eflach@uol.com.br.

${ }^{2}$ De acordo com Koslinski (1998), a Universidade do Professor fez parte de um projeto de capacitação de profissionais da educação do Paraná, iniciado em 1995. O Programa foi financiado pelo Governo do Estado em parceria com o Banco Mundial. O gasto orçamentário em 1996 foi de R\$12.502.478,10 e, até o final do 
primeiro semestre de 1997, de $\mathrm{R} \$ 5.625 .356,01$. Em 1996, este gasto representou 0,39\% da receita e, no período referente a 1997 , representou $0,11 \%$ da receita estadual.

${ }^{3}$ Apenas para exemplificar a questão, no município de Ponta Grossa até o ano de 2002 a educação infantil estava vinculada à Secretaria Municipal de Assistência Social, a qual administrava as creches públicas e repassava recursos para as creches assistenciais (filantrópicas ou comunitárias) realizarem o atendimento educacional. Essa prática ainda persiste no referido município, visto que em 2010 enquanto 38 Centros Municipais de Educação Infantil se encontraram sob a responsabilidade da Secretaria Municipal de Educação, 17 Centros de Educação Infantil mantiveram convênios com o poder público municipal recebendo recursos públicos para manutenção e pagamento de funcionários.

${ }^{4}$ Segundo Aldaísa Sposati "o conceito de desamparado ou necessitado é atribuído à condição de fragilidade física associada à econômica, responsabilizando o Estado de suprir um amparo mínimo a tais cidadãos." (SPOSATI, 1989. p. 8).

${ }^{5}$ Carlos Eduardo Sanches, então presidente da UNDIME-PR, declarou para o Jornal a Gazeta do Povo, em 29/08/2006: "Temos um déficit muito grande de salas de aula, e não podemos assumir o compromisso de ampliação da nossa rede assim tão rápido. No interior, muitas vezes no mesmo prédio funciona uma escola municipal e outra estadual. Nesses locais elas estão superlotadas."

${ }^{6}$ Dos 399 municípios paranaenses, a Decisão Judicial atingiu 391, pois como a Ação foi ajuizada contra o Sistema Estadual de Ensino. Os 8 municípios que já haviam constituído seus próprios Sistemas não foram atingidos diretamente pela decisão: Araucária, Chopinzinho, Ibiporã, Londrina, Ponta Grossa, Reserva, São José dos Pinhais e Toledo.

${ }^{7}$ Como exemplo podemos citar o caso de alunos matriculados na mesma turma de educação infantil (pré, jardim III, ou outra denominação para a última etapa), que completariam 6 anos no mês de maio: aqueles cujos pais pudessem mantê-los em escolas privadas que ofertavam o ensino fundamental de 9 anos, deixariam a educação infantil para ingressarem no ensino fundamental; e, em contrapartida, aqueles que não tivessem as mesmas condições financeiras estariam se inserindo no ensino fundamental de 8 anos e, portanto, deveriam permanecer na educação infantil.

Recebido em março/2012

Aprovado em julho/2012 